\title{
EDITORIAL ZUM REZENSIONSTEIL
}

Die Deutsche Vereinigung für Politische Wissenschaft hat im vergangenen Jahr einen Katalog von „Spezialisierungsrichtungen der Politikwissenschaft“ formuliert, der vor allem der wechselseitigen Orientierung der Mitglieder über ihre jeweiligen Forschungsschwerpunkte dient (vgl. Rundbriefe der Vereinigung). Es erscheint nur folgerichtig, auch die Struktur des Rezensionsteils an diesem Raster auszurichten, wobei jedoch nur die Hauptkategorien verwendet werden:

1. Politische Theorien und Ideengeschichte

2. Methoden

3. Politisches System der Bundesrepublik

4. Politische Soziologie

5. Politikfelder und Politikimplementation

6. Verwaltungswissenschaft

7. Vergleichende Politikforschung

8. Internationale Politik und Außenpolitik

9. Politische Bildung

Wie in allen derartigen Fällen wird auch für zu besprechende Werke die Zuordnung im Einzelnen nicht immer auf der Hand liegen, sondern mitunter davon abhängen, welchen Aspekt man jeweils betont (so taucht etwa im Katalog der DVPW die Unterkategorie „Politische Kultur" sowohl in der Politischen Soziologie als auch in der Vergleichenden Politikforschung auf). Die Leser werden hier um Toleranz und gegebenenfalls Nachsicht gebeten.

Sammelrezensionen werden künftig nicht gesondert aufgeführt, sondern dort, wo sie thematisch hingehören.

Seit März 2001 ist Holger Endrös als Nachfolger von Karsten Grabow in die Redaktion der PVS-Literatur eingetreten. Herrn Grabow danken wir sehr herzlich für seine Arbeit.

Die Redaktion 